\title{
Is the partial pressure of carbon dioxide in the blood related to the development of retinopathy of prematurity?
}

\author{
Balazs Gellen, Neil McIntosh, Janet R McColm, Brian W Fleck
}

\begin{abstract}
Aims-To determine the role of carbon dioxide in the development of retinopathy of prematurity (ROP).

Methods-This was a retrospective cohort study of 25 consecutive infants admitted to the neonatal unit with continuously recorded physiological data. The daily mean and standard deviation (SD) of transcutaneous carbon dioxide partial pressure $(\mathrm{tcPCO})$ was compared between infants who had stage 1 or 2 ROP and stage 3 ROP. The time spent hypocarbic $(<3 \mathrm{kPa})$ and/or hypercarbic $(>10 \mathrm{kPa}$ and $>12 \mathrm{kPa})$ was also compared between these groups. Intermittent arterial carbon dioxide tension was also measured and compared with the simultaneous $\mathrm{tcPCO}_{2}$ data.

Results-There were no significant differences in carbon dioxide variability or time spent hypocarbic and/or hypercarbic between the ROP groups on any day. $86 \%$ of transcutaneous values were within $1.5 \mathrm{kPa}$ of the simultaneous arterial value.

Conclusion- $\mathrm{TcPCO}_{2}$ measurement can be a very useful management technique. However, in this cohort neither variable blood carbon dioxide tension nor duration of hypercarbia or hypocarbia in the first 2 weeks of life was associated with the development or severity of ROP.

(Br F Ophthalmol 2001;85:1044-1045)
\end{abstract}

Child Life and Health, Reproductive and Developmental Sciences, Edinburgh University

B Gellen

J R McColm

Neonatology

N McIntosh

Princess Alexandra Eye Pavilion, Lothian University Hospital Trust, Edinburgh, UK B W Fleck

Correspondence to: Dr Jan McColm, Child Life and Health, Reproductive and Developmental Sciences, Edinburgh University, 20 Sylvan Place, Edinburgh EH9 1UW, UK

Jan.McColm@ed.ac.uk

Accepted for publication 13 March 2001
Retinopathy of prematurity (ROP) is the most commonly acquired retinal disease in premature babies. It is multifactorial, with gestational age ${ }^{1-3}$ and low birth weight ${ }^{14}$ being the most powerful predictors of progression to disease. Although originally it was postulated that high arterial oxygen levels ${ }^{5}{ }^{6}$ were causative, more recently data have shown that fluctuations in arterial blood oxygen tension ${ }^{7}$ are more closely related to the development and severity of the disease.

Clinical studies investigating carbon dioxide have shown both hypercarbia ${ }^{8} 9$ and hypocarbia $^{1011}$ to correlate with retinopathy. Animal studies have established a link to hypercarbia, ${ }^{12}$ but difficultly in inducing hypocarbia has made it difficult to resolve these conflicting data.

The aim of this study was to determine whether hypercarbia or hypocarbia or the variability of carbon dioxide in the first 2 weeks of life in extremely preterm infants were associated with the development of ROP. A criticism of the previous clinical studies was that they used intermittent arterial blood gas analysis to associate $\mathrm{PCO}_{2}$ with pathology, ${ }^{8-11}$ we have analysed continuous transcutaneous carbon dioxide data.

\section{Methods}

This was a retrospective cohort study of infants who were admitted to the neonatal intensive care unit, Edinburgh, between 1996 and 1998. Inclusion criteria were 14 days of continuous monitored data of transcutaneous carbon dioxide, at least stage $1 \mathrm{ROP}$, and less than $1001 \mathrm{~g}$ birth weight or less than 30 weeks gestation.

Infants were divided into two groups, stage 1 or 2 ROP (ROP1,2 group) and stage 3 ROP (ROP3 group). Stage 3 ROP was defined by the presence of extraretinal neovascularisation.

A computerised neonatal cot monitoring system in routine clinical use recorded physiological data including transcutaneous carbon dioxide pressure $\left(\mathrm{tcPCO}_{2}\right)$ from Hewlett Packard combined oxygen and carbon dioxide probes and $78344 \mathrm{~A}$ neonatal monitors. The data were recorded every second and later stored as a 1 minute average of 60 one second data points. After removal of obvious artefact due to probe calibration the mean and standard deviation were calculated for each day of the first 14 days of life. For each period we also noted the number of minutes that the $\mathrm{tcPCO}_{2}$ was under 3 $\mathrm{kPa}$, was over $10 \mathrm{kPa}$, and was over $12 \mathrm{kPa}$. All values were further aggregated over a week or 2 week period to produce a single mean for each statistic for each baby. Arterial carbon dioxide $\left(\mathrm{PCO}_{2}\right)$ tension was also measured intermittently by umbilical or peripheral arterial catheter sample and compared with the simultaneous transcutaneous carbon dioxide data.

Retinopathy of prematurity was diagnosed using binocular indirect ophthalmoscopy with a speculum and scleral indentation. Careful $360^{\circ}$ examination of the peripheral retina up to the ora serrata was performed in every instance, by one of two experienced paediatric ophthalmologists. The first examination occurred at 4-6 weeks post delivery and was repeated weekly until the retina was fully vascularised. ROP was determined using the international classification for ROP..$^{13}$ Data from the infants who were in ROP1,2 group were compared with those who were in ROP3 group by repeated measures analysis of variance (SPSS).

For each baby on each day there was a mean value of $\mathrm{tcPCO}_{2}$ (with artefacts excluded) and a standard deviation (SD). The SDs were then averaged as a measure of variability. The daily means and the daily standard deviations of the babies in the ROP1,2 and ROP3 groups were compared on a daily basis by $t$ test and 


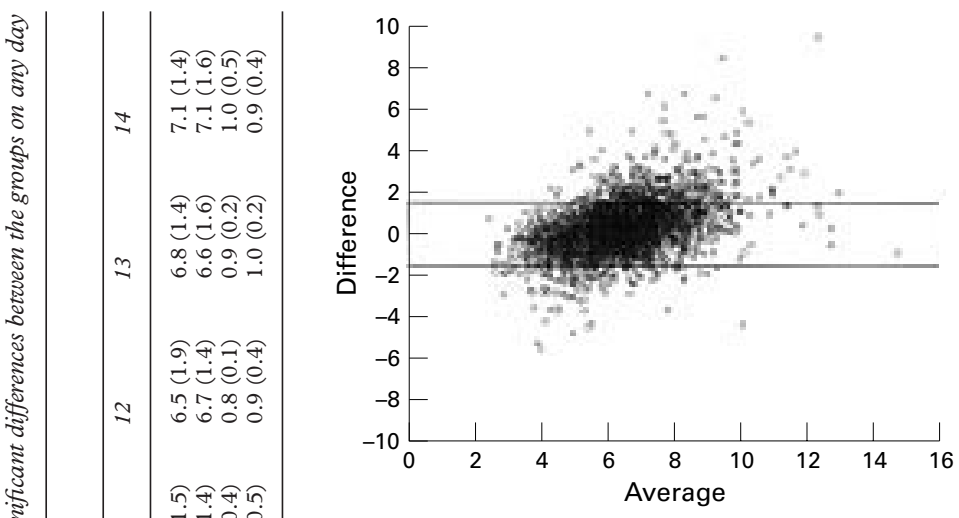$$
\text { 西 }
$$$$
\text { 西 }
$$

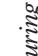

Figure 1 The comparison of transcutaneous and simultaneous arterial $\mathrm{PCO}_{2}$. These data are displayed as a Bland-Altman plot; $85.8 \%$ of transcutaneous values being within $1.5 \mathrm{kPa}$ of the simultaneous arterial value $(1.5 \mathrm{kPa}$ or less difference between tcPCO, and $\mathrm{PCO}_{2}$ was accepted in this study as a satisfactory agreement.) Difference $=$ difference between $\mathrm{PCO}_{2}$ and tcPCO $\mathrm{CO}_{2}(\mathrm{kPa})$ at time of each arterial blood gas measurement. Average $=$ mean of $\mathrm{PCO}_{2}$ and $t_{\mathrm{CPCO}}(\mathrm{kPa})$ at time of each arterial blood gas measurement.

throughout the study using a repeated measures ANOVA (analysis of variance). A Bonferroni correction (with significance defined as $\mathrm{p}$ $\leqslant 0.05$ ) was used because there were a large number of comparisons for the $t$ test.

The time in minutes that the $\mathrm{tcPCO}_{2}$ was $<3$ $\mathrm{kPa},>10 \mathrm{kPa}$, and $>12 \mathrm{kPa}$ was calculated for each infant during week 1 and again during week 2 . The values in ROP1,2 group were compared with ROP3 group using a Student's $t$ test.

\section{Results}

Over the 2 year period 50 infants were diagnosed with any stage of ROP and 25 of these babies met the inclusion criteria, the others failing mainly because of a lack of the 2 weeks of continuous monitoring data. Infants enrolled in the study had a mean birth weight

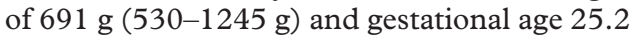
weeks (range 24-29). Ten were in ROP1,2 group and 15 were in ROP3 group.

There was no statistical difference between mean $\mathrm{tcPCO}_{2}$ values or in the variability of $\mathrm{tcPCO}_{2}$ during the first 14 days of life between the two groups (Table 1). The length of time that the $\mathrm{tcPCO}_{2}$ was under $3 \mathrm{kPa}$, was over 10 $\mathrm{kPa}$, or was over $12 \mathrm{kPa}$ was also not significantly different between ROP1,2 and ROP3 group in either the first or the second week of life.

Figure 1 is a Bland-Altmann plot of the intermittently measured $\mathrm{PaCO}_{2}$ versus the simultaneous $\mathrm{tcPCO}_{2}$ data and the differences were not significant; $85.8 \%$ of transcutaneous values were within $1.5 \mathrm{kPa}$ of the simultaneous arterial value, and a difference of $\leqslant 1.5 \mathrm{kPa}$ between $t c \mathrm{PCO}_{2}$ and $\mathrm{PaCO}_{2}$ was accepted in this study as a satisfactory agreement.

\section{Discussion}

The present study does not support the view that either increased variability of blood carbon dioxide or a particular duration of hypercarbia or hypocarbia in the first 2 weeks of life is related to the development or severity of ROP.
In this study blood carbon dioxide levels were measured by a continuous transcutaneous monitoring system for 14 days which is in contrast with other studies that have used intermittent blood gas analysis. To ensure that the transcutaneous measurements were accurate they were compared with the simultaneous but intermittently measured arterial carbon dioxide tension. We found that agreement between the methods was usually excellent and the comparison was clinically highly satisfactory.

The transcutaneous measurements resulted in nearly 20000 data points per baby - each of which in itself was a 1 minute average of 60 one second points. This allowed an objective analysis of the variability of blood carbon dioxide.

The number of infants enrolled in the study was small but the confidence intervals of the results suggest that the lack of difference between groups is unlikely to be related to small numbers creating a type II error. It would certainly be preferable to involve more babies, but during the 2 year period of investigation only 25 infants met the requirements of the inclusion criteria.

The known effects of carbon dioxide tension on small vessel calibre make it inappropriate to discard carbon dioxide as an important factor based on this study alone. Our group has developed an animal model of ROP based on clinically relevant fluctuations in oxygen ${ }^{14} 15$ and we plan to use this to investigate the combination of oxygen variability and hypercarbia on the development and severity of ROP.

We wish to acknowledge the assistance given to us by the clinical staff and thank Dr Elizabeth Wright for her role in the paediatric ophthalmological examination. Dr Gellen was funded by a Royal Society/NATO fellowship.

1 Lucey JF, Dangman B. A reexamination of the role of oxygen in retrolental fibroplasia. Pediatrics 1984;73:82-96.

2 Quinn GE, Johnson L, Abbasi S. Onset of retinopathy of prematurity as related to postnatal and postconceptional age. Brf Ophthalmol 1992;76:284-8.

3 Prendiville A, Schulenburg WE. Clinical factors associated with retinopathy of prematurity. Arch Dis Child 1988;63: 522-7.

4 Kretzer FL, Hittner HM. Retinopathy of prematurity: clinical implications of retinal development. Arch Dis Child 1988;63:1151-67.

5 Ashton N, Path FC. Oxygen and the growth and development of retinal vessels. Am f Ophthalmol 1965;62: $412-35$.

6 Flynn JT, Bancalari E, Snyder ES, et al. A cohort study of transcutaneous oxygen tension and the incidence and transcutaneous oxygen tension and the incidence and
severity of retinopathy of prematurity [see comments]. $N$ severity of retinopathy of prem

7 Cunningham S, Fleck BW, Elton RA, et al. Transcutaneous Cunningham S, Fleck BW, Elton RA, et al. Transcutaneous
oxygen levels in retinopathy of prematurity. Lancet 1995;346:1464-5.

8 Bauer CR. Does carbon dioxide play a role in retrolental fibroplasia. Pediatrics 1982;70:663.

9 Wolbarsht ML, George GS, Kylstra J, et al. Speculation on carbon dioxide and retrolental fibroplasia. Pediatrics 1983;71:859-60.

10 Shohat M, Reisner SH, Krikler R, et al. Retinopathy of prematurity: incidence and risk factors. Pediatrics 1983;72: 159-63.

11 Brown DR, Milley JR, Ripepi UJ, et al. Retinopathy of prematurity. Risk factors in a five-year cohort of critically ill premature neonates. Am F Dis Child 1987;141:154-60.

12 Holmes JM, Zhang S, Leske DA, et al. Carbon-dioxide Holmes JM, Zhang S, Leske DA, et al. Carbon-dioxide
induced retinopathy in the neonatal rat. Curr Eye Res 1998;
$17: 608-16$.

13 International Committee. An international classification of 4 retinopathy of prematurity. Br f Ophthalmol 1984;68:690-7. retinopathy of prematurity simulating preterm oxygen variretinopathy of prematurity simulating preterm oxygen vari-
ability in the rat. Invest Ophthalmol Vis Sci 2000;41:427580 .

$15 \mathrm{McC}$ Colm J, Cunningham S. The development of a computer controlled system to simulate in rats, the rapid, frequent changes in oxygen experienced by preterm infants developing retinopathy of prematurity. $\mathcal{f}$ Med Engineer Technol 2000;24:45-52. 